\section{E-LOGOS}

ELECTRONIC JOURNAL FOR PHILOSOPHY ISSN 1211-0442

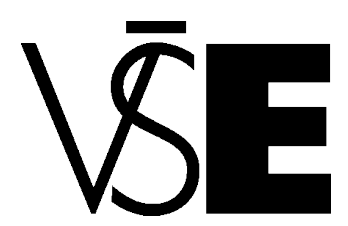

University of Economics Prague

\title{
Relation between Quality of Pleasure and Quantity of Pleasure in J. S. Mill's Theory of Utilitarianism
}

Pavel Janda 


\begin{abstract}
Presented paper critically explores Mill's theory of quality of pleasure. J. S. Mill in his attempt to secure utilitarian position against different adversaries introduced a conception of the quality of pleasure in order to reply to accusations that utilitarianism ends up as a theory suitable only for animalistic part of human nature. Yet, his exposition of the aforementioned principle is far from being lucid. Especially his theory of relation between quantity of pleasure and quality of pleasure suffers from many ambiguous or rather opaque parts. To explore these unclear thoughts is the goal of this paper.
\end{abstract}

\begin{abstract}
Abstrakt
Práce si klade za cíl kriticky prozkoumat teorii J. S. Milla o rozlišení kvalitativní a kvantitativní charakteristice požitků (pleasure). Mill svoji teorii představil jako reakci na kritiku, že utilitární teorie vyhovuje jen zvířecí povaze lidské přirozenost a neuvažuje o vyšších schopnostech lidského ducha. Millova expozice teorie ale není v mnoha pasážích zcela jasná a průhledná. Práce se zaměřuje hlavně na prozkoumání problematického vztahu mezi kvantitativní stránkou a kvalitativní stránkou potěšení.
\end{abstract}

\title{
Key words
}

Mill, quality of pleasure, quantity of pleasure, utilitarianism

\section{Klíčová slova}

Mill, utilitarismus, kvalita potěšení, kvantita potěšení 


\section{Introduction}

J. S. Mill introduced in his work called "Utilitarianism" a conception of the criterion of quality ${ }^{1}$ which may enable us to apprehend pleasure in a new way ${ }^{2}$. Purpose of this paper is to analyze Mill's basic characteristics of the new criterion and point out main difficulties which, in my opinion, render the whole theory untenable. Although I agree with Mill's main idea that it is necessary to sort out pleasures according to the qualitative aspect, I think that his elaboration of this position suffers from significant drawbacks. On grounds of my enquiry I will expose what kind of conditions Mill would have to accept to keep his theory consistent. Furthermore, I will show that if Mill accepted them, he would have to defend a theory which entails uncanny consequences. My enquiry will be based on analysis of a statement which, in my opinion, constitutes the nucleus of the Mill's apprehension of quality.

"If one of the two [pleasures] is, by those who are competently acquainted with both, placed so far above the other that they prefer it even though knowing it to be attended with a greater amount of discontent, and would not resign it for any quantity of other pleasure which their nature is capable of, we are justified in ascribing to the preferred enjoyment a superiority in quality, so far outweighing quantity as to render it, in comparison, of small account."3

The quoted passage provides us with four traits of the qualitative criterion. Firstly, it is said that we need somebody competently acquainted; so called an appropriate judge. Secondly, we know that qualitatively superior pleasure would be preferred even if it were attended with a greater amount of discontent. Thirdly, qualitatively superior pleasure would not be resigned for any quantity of other pleasure (I will call it as the criterion of resignation). Lastly, quality outweighs quantity so much as to render it of small account.

In the rest of my paper, I will try to furnish evidence that these traits are not appropriate to guard Mill's theory and their refusal or modification, with the attempt to preserve Mill's theory as much as possible, leads to a specific apprehension of the quality of pleasure. I will not discuss the second trait because it would need another

\footnotetext{
1 Mill tries to show that we have another criterion to choose among pleasures than quantity of pleasure: "It is quite compatible with the principle of utility to recognize the fact, that some kinds of pleasure are more desirable and more valuable than others. It would be absurd that while, in estimating all other things, quality is considered as well as quantity, the estimation of pleasures should be supposed to depend on quantity alone." Mill, J. S. (1998), Utilitarianism, Oxford University Press, Oxford, pp. 56.

${ }^{2}$ Let us remember that Mill bases utilitarianism on the Greatest Happiness Principle which: "...holds that actions are right in proportion as they tend to promote happiness, wrong as they tend to produce the

reverse of happiness. By happiness is intended pleasure, and the absence of pain..." Mill, J. S. (1998), Utilitarianism,

pp. 55.
}

${ }^{3}$ Mill, J. S. (1998), Utilitarianism, pp. 57. 
profound consideration, which would extend this paper too far from its original idea and herewith this trait has, from all aforementioned traits, strictly speaking, the least connection with my main topic (relation of quantity of pleasure and quality of pleasure). My main thesis is, as has been already stated in a more general way, that by holding Mill's theory we (or Mill himself) would have to accept certain and specific understanding of quality of pleasure, which is not conclusive and, as I believe, even plausible.

\section{Convertibility of Pleasure}

Let us first consider the fourth trait which adverts to relation between quality of pleasure and quantity of pleasure. Mill's distinction of quality and quantity in pleasure has to be based on one crucial supposition, which Mill does not, however, explicitly mention. He must not admit any possible measurability (reducibility) between quality of pleasure and quantity of pleasure. If there was any plausibility to find out or estimate a ratio between quality and quantity we could, then, draw a transfer table. In other words, we could express quality in quantitative terms and whole distinction would loose its effect because quality would be only differently expressed quantity. Even if Mill does not make a direct reference to this condition he tries to secure it in a few ways. That Mill cannot allow the quality of pleasure to be expressible in the terms of the quantity of pleasure will serve us as a starting point. This aim will consequently lead me firstly to examine the relation between quality of pleasure and quantity of pleasure and later on between quantity of thing which produces any pleasure and quality of pleasure. Let us now closely approach a problematic situation which is caused by possible reducibility of quality of pleasure into quantity of pleasure.

I believe that it is vital to avoid convertibility between quality of pleasure and quantity of pleasure because if such a situation happened, all Mill's effort would be nugatory ${ }^{4}$. In other words, for example let us suppose reading a book produces certain amount of quantity of pleasure and certain quality of pleasure. If we had a possibility to express quality of pleasure in the terms of the quantity of pleasure, we could, then, prefer one thing to other because of quantity of pleasure it causes. It means that we prefer reading book because of quantity of pleasure it produces. Then,

\footnotetext{
${ }^{4}$ Mill's aim is to avoid an accusation that:" Now, such a theory of life excites in many minds and among them in some of the most estimable in feeling and purpose, inveterate dislike. To suppose that life has (as they express it) no higher end than pleasure- no better and nobler object of desire and pursuit- they designate as utterly mean and grovelling; as a doctrine worthy only of swine..." To avoid such conclusion and to confirm that: "Human beings have faculties more elevated than the animal appetites, and when once made conscious of them, do not regard anything as happiness which does not include their gratification..." Therefore, if we accept the reducibility of quality of pleasure into quantity we risk that utilitarianism could be again accused of being the theory suitable for swine. Mill tends to base utilitarian defense on the firm ground. Mill, J. S. (1998), Utilitarianism, pp. 55-56.
} 
Mill has to face a very disturbing situation. If things produce quality of pleasure and quantity of pleasure and quality of pleasure is expressible in (can be reduced into) the terms of the quantity of pleasure, we can order these things according to the quantity of pleasure they produce.

We could ask, what does it mean that quality of pleasure renders quantity of pleasure of small account? In the situation when there is a possibility of conversion of quality of pleasure into quantity of pleasure, it means that by converting even small level or amount of quality of pleasure into quantity of pleasure we gain a great amount of quantity of pleasure. If it is so, then e. g. reading a book (considered as having high quality of pleasure) if expressed only in quantity of pleasure would produce much higher quantity of pleasure then for example drinking alcoholic beverages (considered as having low quality of pleasure).

If we follow aforementioned course, then everybody, who maximise pleasure including those who consider only quantity of pleasure, have to choose the same thing (in our example reading a book) because it produces higher of pleasure. It can be said because it produces higher quantity of pleasure since we can transfer quality of pleasure into quantity of pleasure. In other words, everybody will prefer reading a book to drinking alcoholic beverages and if not he is not maximizing his pleasure. We face here two difficulties. Firstly, this conclusion contradicts our experience. Secondly, choosing only according to quantity of pleasure should be according to Mill avoided. Therefore if we enable any possible conversion we face a situation which provides results which does not agree with reality and an issue which should be avoided. Therefore we have to enquire, by which manners Mill tries to avoid possible conversion of the quality of pleasure into the quantity of pleasure. Mill's idea that quality renders quantity as unimportant may be significant in considering the certain relation between quantity and quality but it is not very helpful to avert the danger of possible conversion of quality into quantity - I think it has only a dissuasive influence. And this danger must be averted in the first place if we want so save Mill's theory.

When Mill proclaims that quality surpasses quantity in such a way as to render it of small account, it seems that this statement does exactly the opposite of what it is supposed to accomplish. In stead of building an impenetrable barrier between quantity and quality of pleasure, it places them into a relation. Yet, Mill's argument aims at something rather different. If we accept that enjoyment is superior in quality when it outweighs quantity as to render it of small account, there is no need to proceed with mutual comparison of quality and quantity.

The fact is that in this case Mill only dissuades from exploring precise ratio between quality and quantity by revealing the partial answer. On the other hand, Mill's argumentation indicates that the relation between quantity and quality may 
exist. It seems that quality and quantity are in some kind of proportional relation because quality renders quantity as unimportant. The question is whether the relation between quantity of pleasure and quality of pleasure allows us to find a particular example with a turning point where additionally increased quantity of pleasure could surpass quality of pleasure ${ }^{5}$. Possibly then, we could find other instances and their turning points that would enable us to construct an approximate conversion table between quality of pleasure and quantity of pleasure. That is exactly the situation which endangers Mill's theory. If somebody argued that by adding the quantity of pleasure the quality of pleasure would also rise (or change in any direction) we would reach the answer. We would have the measure whereby we could translate quality of pleasure into quantity of pleasure. In other words, no quality change could be correlated to quantity change. If we, ceteris paribus, add quantity of pleasure, quality of pleasure can not change. If it does, then, there is a discernible relation and possibility of conversion of quality into quantity ${ }^{6}$.

${ }^{5}$ Let us consider two lower pleasures (we know that one pleasure is preferable), both with quantitative and qualitative aspect. To mention the most obvious example we will assume that the pleasure $A$ is preferable and in comparison to pleasure $B$ pleasure $A$ provides less quantitative and more qualitative pleasure. Than we can, as first and rather intuitive method, add quantitative parts until we will able to surpass the $A$ pleasure by $B$ pleasure. This is possible but doesn't give directly clear result considering amount of quantitative pleasure which had to be added (the relationship between quantity and quality). The second course supposes to process more abstractly but with much overt result. Let us imagine that we manage to subtract from both pleasures $(A$ and $B$ ) that quantitative part which is smaller. Now on one side we have only qualitative aspect and on the other quantitative and qualitative aspect. Let us suppose that $A$ (which lost its all quantitative aspect) is still preferable to $B$. Then we will add to $B$ always the same part (we create unite of measure - we add the quantity which remained after subtraction). In this way how many units have to be added to surpass the $A$ pleasure by $B$ pleasure.

${ }^{6}$ I will show what I mean by using a more concrete example. The following example is meant mostly as an illustrative one and very probably contains many simplifications. Let us accept that we can distinguish between quality of pleasure and quantity of pleasure. Let us further accept that we can express the magnitude of both pleasures (understood as mathematical quantities) and that the quantities of the same kind may be added together. Then, if one thing produces a total pleasure which is for this particular instance defined as a combination of quality of pleasure (QIP) and quantity of pleasure (QnP) we can write $\mathrm{TP}=\mathrm{xQlP}+\mathrm{yQnP}$, where $\mathrm{x}$ and $\mathrm{y}$ are numbers expressing height, level or anything expressing the magnitude of the quality and quantity of pleasure. Then, we could find two things which produce the same total pleasure $\mathrm{TP}_{1}=\mathrm{TP}_{2}$. It means that $\mathrm{xQlP}+\mathrm{yQnP}=\mathrm{cQlP}+\mathrm{zQnP}$ which leads to $\mathrm{QlP}=\mathrm{QnP}(\mathrm{z}-$ $\mathrm{y}) /(\mathrm{x}-\mathrm{c})$. Here we have a precise ratio between quality of pleasure and quantity of pleasure and we can express quality of pleasure in the terms of quantity of pleasure. ${ }^{6}$ We can write this equation for any two pleasures with equal total pleasure. If there is a general determinate relationship between quality of pleasure and quantity of pleasure (e.g. if quantity of pleasure rises then quality of pleasure rises by certain amount) then we will always reach the same result expressing the relation between quality of pleasure and quantity of pleasure. In other words, the fraction $(x-c) /(z-y)$ or $(z-y) /(x-c)$ will always bring the same result for all instances and will enable us to determine the precise relation. Yet, if there is no correlation between quantity of pleasure and quality of pleasure we will not be able to determine a general result applicable for all instances. Still, no correlation between quality of pleasure 


\section{Resignation of Pleasure - Interpretation}

Disproportion between quantity and quality of pleasure seem to be also secured by the third trait which treats the possibility/impossibility of resignation ${ }^{7}$ of one pleasure for another. According to Mill's definition the pleasure superior in quality would be never resigned for any quantity of other pleasure. It seems that Mill denies any possibility of surpassing quality by quantity after all. I will try to prove that Mill's definition cannot be used as a general rule because we can find a case in which it leads to a contradiction.

It is important to enquire what Mill really means by his criterion of resignation of pleasure $^{8}$. We know that it is supposed to help us to determine which pleasure is qualitatively higher. Every decision of the height of the quality of pleasure can be expressed (reduced) by means of the comparison of two pleasures: we compare if we would resign one particular pleasure for any quantity of other particular pleasure. It is natural that we do not know which pleasure is qualitatively higher, if we knew the test would be futile. The test may proceed subsequently. We compare one pleasure with the maximum quantity of other pleasure. If we decide that we would not resign the first one for the maximum quantity of the other it could be entailed that the first one is qualitatively higher than the second one because if it is not resigned for the maximum quantity we would not resign it for any quantity.

and quantity of pleasure is only one of necessary conditions which prevent a possible conversion of quality of pleasure into quantity of pleasure.

7 I find that the criterion of the resignation of pleasure is very significant. Even if it would be meant as a mere figure of speech it is still a part of the most important sentence which defines the quality of pleasure. Moreover, I believe that it is more coherent to enquire Mill's own words and endogenous part of Mill's theory than trying to implement some exogenous assumption. Even if we accept the criterion of appropriate judges, we have to determine the nature of experience meant by Mill. Otherwise we fall into a vicious circle: some pleasure is higher because appropriate judges say so and who does not agree is not an appropriate judge etc. From this point of view, I believe that criterion of the resignation of pleasure may be used as an appropriate criterion of judge's experience and its advantage is that, as said, it is endogenous to the Mill's theory. From these reasons I believe that the following enquiry is appropriate. Then, according to this criterion experienced judge went through so many comparisons between pleasures that he can determine which one he would never resign for any quantity of other pleasure.

8 Let us properly define used terminology. By the term "any quantity" I will understand the highest possible quantity of pleasure. Hereby if we refuse to resign qualitatively superior pleasure for the maximum quantity of other pleasure, then we would refuse it for any quantity lower than maximum. By the term "other pleasure" I understand any kind of pleasure which is conceived as qualitatively inferior. The general assumption is that we want to maximize our pleasure. 
For examined case, the maximum quantity of pleasure may be understood as maximum number of things or as maximum pleasure they may cause. In the first example it is possible to understand it as maximum of things which I can consume even if my pleasure from consuming is diminishing. But such position cannot be accepted since we maximize our pleasure. In the second case to consume the maximum means to reach a level of satisfaction when another unit consumed produces marginal utility equaled to 0 or negative. This approach is acceptable because we seek and reach the maximum pleasure. Therefore we have to ask if we are willing to resign pleasure $\mathrm{A}$ for, in the second way defined, any maximum quantity of pleasure of $B$. This approach has an advantage that if we determine that we would not resign pleasure A for maximum quantity of pleasure B than we would not resign it for any other quantity of pleasure B. Vice versa, if we resign pleasure A for some, lower than maximum, quantity of pleasure from B then, we would certainly resign it for maximum quantity of pleasure from $\mathrm{B}$.

It would be more accurate to say that by not resigning one pleasure for any quantity of other pleasure we only keep the possibility that scrutinized pleasure is the higher one (qualitatively) but such a comparison does not prove that one pleasure is qualitatively higher than the other one. It is truth and it will be examined and proved that we need to add another criterion to decide about qualitative relation between two pleasures. Yet, in practice it is impossible to compare all the pleasures together and reach an absolute knowledge and therefore, for everyday life, we need an operative criterion. Secondly, if we do not accept the criterion of resignation as criterion which decides between two particular pleasures but as a criterion assigning pleasure to two different and absolute categories (lower and higher pleasures) we will reach another type of decision based on quantity of pleasure, however, this time based on the two-level schema. In other words, the decision would be based purely on the quantity of pleasure only applied on two different levels of pleasures ${ }^{9}$.

I will explain the difference. If we accept an operative criterion we will gain, maybe, an infinite series of pleasure ranked according to the height of quality. In this ordered series the law of transitivity must be valid. It may seem that in this manner we postulate that the most supreme pleasure (concerning quality) exists. Yet, this is true only if we understand our series as static one (taken in one moment and no changes permitted). If we accept it as the dynamic structure there will not be (even if it cannot be fully precluded) any firmly rooted supreme pleasure. By dynamic structure I mean changes which may affect our perception of pleasure (e. g. new information about its effects) or appearing of new pleasures. In this model situation we may choose among pleasures according to their quality. On the contrary, if we accept the absolute interpretation we will be able to determine two levels of

\footnotetext{
${ }^{9}$ I will call it as an absolute interpretation of the criterion.
} 
pleasures differentiated by their level of quality. Yet inside these two levels we will not be able to follow any qualitative distinction and we will have to find another criterion which will enable us to choose among different pleasures. I tend to think that in order not to add something new into the theory this measure would be based on the quantity of pleasure. This will be more deeply enquired in the following sections.

Then, if we find that we would never resign some pleasure (pleasure A) for any quantity of other pleasure (pleasure B) we have a reasonable believe that the first pleasure may be qualitatively higher than the second one. In this comparison, we have three possible outcomes. The first possibility is that we are right and pleasure A is really qualitatively higher than pleasure B. Other two possibilities are that both pleasures are either qualitatively higher or qualitatively lower. If one of these two possibilities occurs we would have to find another criterion which would decide among pleasures on both levels. If we are unable to distinguish among them and therefore choose, we may end like "Buridan's ass". Because we maximize our pleasure and the quality cannot be used as differentiating principle we can use as a principle either quantity of pleasure or we can correlate a quality to some magnitude (e. g. number of things consumed) and suppose that we may somehow amplify the quality of pleasure by consuming more and more things. This amplifying of quality would not mean changes in the level of quality (we would be still on the one of two levels lower/higher) but rather it would amplify the quality of pleasure inside the appropriate level (I would call it the quantity of quality). Yet, I do not know and see any way which would allow such procedure, which, I believe, seems rather implausible.

However, in both cases we are dealing with direct or indirect quantity of pleasure and we fall back to the situation in which we choose according to the quantity of pleasure. We should remember that in the realm of Mill's theory we try to avoid such situation. It can be avoided, as said, if we accept that the criterion of resignation is a determinant criterion between two particular pleasures and if we want to determine which one is (at least more possibly) qualitatively higher only relatively to each other - for practical use (it means only with certain probability). In this way we can really choose according to quality of pleasure and not according to quantity of pleasure only in two different levels. It seems that this interpretation is also in accordance with the beginning of the cited sentence which stands as a base for my enquiry because it starts with: "Of two pleasures... ${ }^{10 "}$

${ }^{10}$ Mill, J. S. (1998), Utilitarianism, pp. 56. 


\section{Resignation of Pleasure - Application}

Therefore I prefer to examine the criterion of resignation as the criterion of decision about qualitative relation between two pleasures than as criterion of assignment of pleasures into two levels of quality. To compare both pleasures we need a common denominator otherwise we could compare incomparable. Here we face a problematic situation. On the one side of comparison we have maximum quantity of pleasure but on the other side we have only further unspecified "pleasure", which may be at most assumed as qualitatively higher. Yet, still its qualitative position may be only assumed and as such can not be used as determinant in the comparison. Moreover, if we compared directly two qualities of pleasure we would not need any quantity of pleasure. Yet, we do not know qualitative positions (if the quality is high or low and how high or how low) of compared pleasures. In accordance with Mill we will accept maximum quantity of pleasure as one side of the comparison.

We have three possibilities to fill the other side in comparison. It can be quantity of pleasure, quality of pleasure and quality of pleasure and quantity of pleasure together. Second and third possibility suffers from two vital drawbacks. Firstly, as said, we do not know the quality of pleasure. And, secondly, even if we knew it, such a comparison with quantity of pleasure, which we accepted as one part of the comparison, would call, in accordance with the requirement of the principle of common denominator, to translate quality of pleasure into quantity of pleasure. As have been shown in the previous paragraphs of my work, to avoid the possibility of conversion of the quality of pleasure into quantity of pleasure is vital condition for whole theory. Then, only possibility we are left with, is to put on the other side of comparison the quantity of pleasure. However, this possibility, as will be shown, leads to contradictory results.

I will simulate a very simple model situation ${ }^{11}$. I will use basic economical terms to simplify the example and to show that my thoughts are expressible in generally accepted terms. As have been shown we have to supply both sides of comparison with the quantity of pleasure. As a quantity of pleasure I will use concepts of marginal utility (MU) and total utility (TU). Let us have two pleasures: consuming apples and drinking scotch. Using this example, I will examine whether it is possible to determine the qualitative superiority according to the aforesaid principle. First consumed apple brings to the consumer $\mathrm{MUa}_{1}=6$ utility and marginal utility of any other unit is $\mathrm{MU}_{\mathrm{n}}=1 / 2^{*} \mathrm{MU}_{\mathrm{n}-1}$ where $\mathrm{n}=1, \ldots, 4$ and " $\mathrm{n}$ " indicates the number of consumed apples and " $a$ " is a symbol for "an apple". If $\mathrm{MUa}_{1}=6$ then $\mathrm{MU}_{2}=3$ and so

${ }^{11}$ Ditto, this example is rather a simple one (it is based on simple suppositions like additivity of pleasure and reducibility of pleasure into numeric expression tec. Yet, it provides an insight in the argumentation. In such case its simplicity should not be seen as inadequate. It shows that we are able to build up even very simple model, which contradicts Mill's conclusion. 
on. First scotch brings $\mathrm{MUs}_{1}=9$ and any other $M \mathrm{Ms}_{\mathrm{n}}=1 / 3^{*} \mathrm{MUs} \mathrm{s}_{\mathrm{n}-1}$ where $\mathrm{n}=1, \ldots, 4$ and " $n$ " indicates the number of consumed glasses of scotch and " $s$ " is a symbol for "scotch". Let us, for simplicity, suppose that only four units of one article or both together can be consumed before marginal utility becomes negative. We can, then, count the maximum total utility which can be reached by consuming scotch, which is 13 and $1 / 3$ and the maximum total utility which can be reached by consuming apples, which is 7 and 9/12.

Generally, it seems probable that considered pleasure can be in one comparison higher and in another one lower. It means that e. g. reading a detective novel is qualitatively higher than drinking alcoholic beverages but it is qualitatively lower than reading Byron's poetry. In other words, a series of pleasures is created according to their quality. Yet, it would be rather strange if in the one comparison the pleasure would be once higher and once lower, depending on question we ask. This is the case of given example. Generally speaking, in such instances it does matter if we ask "Would we resign A for the maximum quantity of pleasure B?" or "Would we resign B for a maximum quantity of pleasure of A?" because the answer depends on the order of asked questions. Let us have a look at the concrete example.

Would we be prompted to resign all scotch to have 4 apples which maximize our total utility? We would not because by combining two apples and two glasses of scotch we can reach $\mathrm{TU}=21$, which is grater than $\mathrm{TU}=7$ and 9/12. Since we would not resign pleasure of drinking scotch for any quantity of pleasure from eating apples it entails that pleasure from drinking scotch is qualitatively superior to pleasure from eating apples. Now, would we resign pleasure from eating apples for 4 glasses of scotch which maximize our total utility? Again, we would not because combining this time e. $g$. one apple and three glasses of scotch brings $T U=19$, which is grater than $\mathrm{TU}=13$ and $1 / 3$. Because we would not resign pleasure of eating apples for any quantity of pleasure from drinking scotch it entails that pleasure from eating apples is qualitatively superior to pleasure from drinking scotch. Overall, the conclusion is that pleasure from drinking scotch is qualitatively superior to pleasure from eating apples and at the same time pleasure from eating apples is qualitatively superior to pleasure from drinking scotch. To sacrifice one for the other in either case would be a suboptimal choice

In fact we reach this result many times because to reach a non-contradiction we would have to find a pleasure which fulfil certain conditions. Let us briefly examine what I mean. Let us have two pleasures $A$ and B. Let $n$ be the maximum number of certain thing we can consume before we stop getting pleasure from it. In other words, pleasure from $n+1$ unit is 0 or negative. For pleasure $A$ to be considered as qualitatively higher, in accordance with former conclusions, has to stand that pleasure from 1 to $\mathrm{n}$ unit of $\mathrm{A}$ has to be greater than from any combination of 
pleasure A and B. Then, would we sacrifice A for any (maximum) quantity of pleasure from $B$ ? In this case we would not be willing to sacrifice A for any quantity of pleasure of B. Yet, we must ask if we would not sacrifice B for any number of A? If we say "no", we have to face the same problem as before (results depending on the order of questions). Therefore, we have to say "yes" to avoid contradictory conclusion. In other words, we would sacrifice B for any quantity of pleasure from A. Only in this way we can say that A is in fact qualitatively higher than B and this determination does not depend on the order of questions. Why would we sacrifice $B$ for any quantity of pleasure from A? We cannot answer this question in the field of the criterion of resignation and we have to move further. I believe that, after all, criterion of resignation is, within the frame of the whole Mill's theory, expendable.

In addition, this result may be also interpreted as breaking the logical law of transitivity. Let us have both pleasures (eating apples and drinking scotch) as defined and let us take another pleasure: reading a book. Pleasure from reading a book is defined as $\mathrm{MUr}_{\mathrm{n}}=1 / 4^{*} \mathrm{MU}_{\mathrm{n}-1}$ and $\mathrm{MUr}_{1}=12$ and again the maximum number consumable is 4 units (for example 4 hours of reading). For pleasure reading we get $\mathrm{MU}_{2}=3, \mathrm{MUr}_{3}=3 / 4$ and $\mathrm{MUr}_{4}=3 / 12$. This give us $\mathrm{TU}=16$ for maximum number of hours (four hours). Law of transitivity states that if $A>B$ and $B>C$ then $A>C$. We have seen that we can arrange that eating apples may be qualified as qualitatively higher than drinking scotch. We can ask: "Would we resign drinking scotch for any quantity of pleasure from reading?" If we maximise pleasure the answer must be negative because by combining one scotch and one hour reading we gain $\mathrm{TU}=21$ which is higher than pleasure from four hours reading. Therefore drinking scotch should be qualitatively higher pleasure. Yet, we can ask: "Would we resign reading a book for any quantity of pleasure from eating apples?" The answer must be also negative because from eating apples my maximum utility is 7 and $9 / 12$. From consuming one apple and reading for an hour my $\mathrm{TU}=18$.

It would be a suboptimal choice to resign reading a book for any quantity of pleasure from eating apples. Therefore it seems that reading a book is qualitatively higher than eating apples. Yet, according to the law of transitivity such a situation cannot happen. In other words, it cannot happen that eating apples is qualitatively higher than drinking scotch, drinking scotch is qualitatively higher than reading a book and reading a book is qualitatively higher than eating apples.

\section{Quantity of the Object}

However, I believe that we can try to find another way which will keep the importance of the quality of pleasure. To cause preference of any quantity of pleasure of $\mathrm{A}$ to $\mathrm{B}$ has to have a cause and it is rather improbable that it would be due to quantity of pleasure because it would provide us with very low number of possible 
examples. I will try if the quality of pleasure may provide sufficient criterion. Then, the fourth trait which states that quality of pleasure renders quantity of pleasure of small account would be also fulfilled. An influence of this trait can be seen in the conclusion that we would resign pleasure B (even its maximum pleasure) for any quantity of pleasure of A.

Yet, I have said that quality of pleasure can not be connected with quantity of pleasure and now I seem to put them into the relation. Furthermore, it seems that we try to employ quality of pleasure into decision, when it was stated that it can not be done. In other words, when we say that we would prefer any quantity of pleasure of A to B because of quality it seems that quality and quantity of pleasure are related. Yet, it is not necessary because they may simply coincide depending on one common ground, which may be the quantity of thing which causes pleasure. Therefore we have to discuss the relation between quality of pleasure and quantity of thing which produces pleasure. However, the criterion of resignation of pleasure for certain quantity of other pleasure remain futile because if we correlate quality of pleasure with quantity of objects which produce pleasure we can decide about qualitative relation by direct comparison of qualities of pleasures and the criterion of resignation is not needed.

I have exposed why quality of pleasure can not be related to quantity of pleasure and that one of Mill's attempts to secure this position is not coherent. Nevertheless, it seems that quality of pleasure may be closely connected to another type of quantity, the quantity of the object which causes pleasure. Relation of quantity of object and quality of pleasure becomes significant concerning discussion about appropriate judges, accordingly to the first trait. Mill defines an appropriate judge as somebody who is "competently acquainted with both [pleasures] 12 " or those "who are qualified by knowledge of both [pleasures]13". This sort of knowledge is according to Mill based on experience, which, as a knowledge gained by repeated trials, by definition refers to quantity in question. In that case, appropriate judge appears to be somebody who lived through enough (certain quantity of) trials.

We can try to simulate the process of experiencing when it is supposed that quality of pleasure has relation to quantity of object. Let us have two objects (e. g. an apple and a book) which cause quantity ${ }^{14}$ of pleasure and quality of pleasure and let suppose that eating an apple brings less/worse/lower grade of qualitative pleasure than one minute of reading 15 . If we accept that quality of pleasure changes with

\footnotetext{
12 Mill, J. S. (1998), Utilitarianism, pp. 55.

13 Mill, J. S. (1998), Utilitarianism, pp. 58.

${ }^{14}$ For this example I will not consider any involvement of quantitative pleasure.

${ }^{15}$ Here may raise a question about propriety of comparison such different units as time and units of apples. We could talk about number of apples eaten and number of sentences (or words read) but it
} 
quantity of object and we leave quantity of reading unchanged and increase quantity of apples eaten, quality of pleasure from reading $\left(\mathrm{QP}_{\mathrm{r}}\right)$ should remain unchanged and quality of pleasure from eating apples $\left(\mathrm{QP}_{\mathrm{e}}\right)$ should change. We get three possible outcomes: $\mathrm{QP}_{\mathrm{r}}=\mathrm{QP}_{\mathrm{e}} ; \mathrm{QP}_{\mathrm{r}}<\mathrm{QP}_{\mathrm{e}}$; $\mathrm{QP}_{\mathrm{r}}>\mathrm{QP}_{\mathrm{e}}$, which provide two possible interpretations.

First two results evince that by increasing the quantity of objects we can gain a higher quality of pleasure ${ }^{16}$ and in this particular instance (judging according to quality of pleasure) we had rather choose eating certain amount of apples instead of reading a book for one minute ${ }^{17}$. In addition, we have gained another possibility of conversion of quality of pleasure into quantity but this time it is quantity of objects. We can write an equation: quality of pleasure from eating $\mathrm{x}$ apples = quality of pleasure from 1 minute reading. The third result is a quite different case. Eating apples either cannot qualitatively surpass reading at all or we have not eaten enough apples to reach demanded level of quality. In the second instance we can try to reach a qualitative level by eating more apples but in the first instance we have to conclude that quality of pleasure from eating any quantity of apples can not surpass quality of pleasure from one minute reading.

Generally speaking, if we could find an instance where $x$ units of pleasure $A$ bring lower quality of pleasure than $y$ units of pleasure $B$ and $x+q$ units of $A$, where q stands for any quantity added, bring higher quality of pleasure than y units of $B$, then we cannot talk in all instances about clearly distinct higher and lower pleasures. If Mill wanted to deny that such a situation may occur, he would have to defend almost ridiculous situations like: one second reading brings qualitatively higher pleasure than one glass of wine. This is an extreme example but we could go even more into the extremity (e. g. talking about one tenth of a second of reading) only to evince what kind of strange situations rises. Judging from experience, we should base our decision making on quantity of units which would - as described above preclude a possibility to classify all pleasures distinctly into two groups as higher or lower pleasures. Naturally, I do not say that there can not be pleasures which in all instances provide higher qualitative pleasure than others. On the other hand, under given circumstances a relationship in question may be only relative, which means depending on quantity of units which provide pleasure. Conclusions of current discussion seem to be in accordance with the conclusions of discussion about resignation of pleasure. Yet, they directly contradict our everyday experience. Concretely speaking, I believe that, judging accordance to one's experience, we do

seems to more artificial and abstract than the first manner mentioned. General discussion about comparability of different units exceeds potentiality of this paper.

${ }^{16}$ Or equal qualitative pleasure but it means that we could get the higher one.

${ }^{17}$ It can be argued that one minute reading is not a reading. Yet, I try to choose extreme examples to clarify the idea. 
not have greater pleasure from one second of reading than from eating one apple even if we would consider reading as higher pleasure. It then contradicts the conclusion that we would resign one pleasure for any quantity of qualitatively higher pleasure.

\section{Conclusion}

It does not seem that Mill would accept such relativity because he writes about distinction of pleasures in general and in a relativistic perceiving we would always have to refer to quantity of objects causing pleasure and not only to general pleasure. Moreover, he does not say anything in the sense that one pleasure could be qualitatively higher than other on one occasion but not on the other. On the contrary by denying general willingness to resign qualitatively higher pleasure for qualitatively lower pleasures he seems to hold the position of the clear distinction between higher and lower pleasures. In that case he has to find a criterion for this distinction and therefore, higher and lower faculties are introduced. Then, we can hold a view that superiority in quality arises out of the employment of higher faculties ${ }^{18}$ and inferiority comes from the employment of lower faculties.

However, even in this case we have to reject a relation between the quality of pleasure and quantity of employment of either higher or lower faculties. Otherwise we would affront the same objections, which were raised when the relation between the quality of pleasure and quantity of units causing it was discussed. Considering all this, we have to ask what happens to appropriate judges and their knowledge based on experience? According to my reasoning, in order to be experienced and consequently an appropriate judge is sufficient to know, considering particular pleasures, which one of the faculties is employed. Hence, the conception of quality of pleasure would be a mere denotation of this relationship and to talk about quality of pleasure means to talk about this relation. The truth is that such a realization really may require repeated attempts and hence profound experience as being postulated by Mill.

This slight shift creates an absolutely new situation. Since the quality of pleasure can be connected neither with quantity of pleasure nor with quantity of

\footnotetext{
${ }_{18}$ Mill does not give a precise definition of lower and higher faculties. Yet, it could be deduced that lower faculties are closely connected to sensual pleasure and higher faculties to mental pleasures: Now it is an unquestionable fact that those who are equally acquainted with, and equally capable of appreciating and enjoying, both, do give a most marked preference to the manner of existence which employs their higher faculties. Few human creatures would consent to be changed into any of the lower animals, for a promise of the fullest allowance of a beast's pleasures; no intelligent human being would consent to be a fool, no instructed person would be an ignoramus, no person of feeling and conscience would be selfish and base, even though they should be persuaded that the fool, the dunce, or the rascal is better satisfied with his lot than they are with theirs. Mill, J. S. (1998), Utilitarianism, pp. 56-57.
} 
things producing pleasure it seems not to be the part of pleasure itself. If in the relation (maybe simplified): pleasure - our being, the quality of pleasure is not part of the pleasure it must be part of our being. In other words, quality of pleasure is produced by us (by some our functions) and outside pleasures are only some kind of triggers. Yet, it means that we could possibly feel quality of pleasure without any outside pleasure. The pleasure itself is not higher or lower, it rather seems only as a trigger which switches on our higher/lower qualities which are the source of quality of pleasure. It could be, I think, well showed when quality of pleasure and quantity of pleasure are compared.

Yet, we face new serious difficulties; especially three of them are very disturbing. We again face the situation that we have two levels of pleasures (higher/lower quality) even if now conceived us mere triggers (sorted according to which faculties stimulate). We will have problem to choose (differentiate pleasures) inside these two levels. If we accept quantity as the criterion inside these levels we return to decision based on quantity of pleasure only applied on two levels. Secondly and mainly, we have to face the situation that if we have e. g. some kind of drug which stimulates our higher functions and it causes higher pleasure (measured by chosen -here not defined-criterion) than for example reading poetry we should choose the drug. In other words, by separating so called quality of pleasure from pleasures and place it into our higher/lower faculties we distinguish pleasures only according their stimulating potential and here some drug may surpass for example reading poetry. Therefore we have to leave the main purpose of Mill's distinction of quality of pleasure and quantity of pleasure. Thirdly, some of our conclusions made during our enquiry may be applied on higher/lower functions as well: for example the relation between quantity of thing which produces pleasure (here quantity of use of our faculties) and quality of pleasure. All this would need new and profound enquiry.

Nevertheless, this attitude brings up new questions, which would deserve the entirely new enquiry (i.e. which criterion will be used to decide ${ }^{19}$ between two qualitatively higher (lower) pleasures in each group). In this work I tried to enquire the relationship between quality of pleasure and variously conceived quantities: quantity of pleasure and quantity of objects causing pleasure. I tried to expose that taking Mill's theory of the quality of pleasure and the quantity of pleasure as a point of departure, we come to the conclusion that quality of pleasure can not be related either to quantity of pleasure or quantity of units causing pleasure and that we have

19 We would have to know either something which may cause differences between higher (lower) pleasures or simply use quantity as criterion of pleasure. This time, using quantity would be secured by the situation in which the level of quality of pleasure remains the same in each group (lower/higher pleasures). 
to conceive the quality of pleasure as a matter of relationship between pleasure and the type of employed faculties. However, this conclusion has introduced new questions, which would have to be explored before acceptance or refusal of this approach. As I have already said at the beginning of the presented paper, the enquiry showed that quality of pleasure has to be perceived in a specific way, which completely alters Mill's theory. 


\section{Bibliography}

Fitzpatric, J. R. (2006), John Stuart Mill's Political Philosophy: Balancing Freedom and the Collective Good, Kontinuum, London.

Hamburger, J. (1999), John Stuart Mill on Liberty and Control, Princeton University Press, Princeton.

Heydt, C. (2006), Rethinking Mill's Ethics: Charakter and Aesthetic Education, Continuum, London.

Marshall, H. R. (1989), The Classification of Pleasure and Pain, Mind, Vol. 14, No. 56 (Oct., 1889), pp. 511-536.

Mezes, S. E. (1895), Pleasure and Pain Defined, The Philosophical Review, Vol. 4, No. 1 (Jan., 1895), pp. 22-46.

Mill, J. S. (1998), Utilitarianism, Oxford University Press, Oxford.

Rice, P. B. (1943), Quality and Value, The Journal of Philosophy, Vol. 40, No. 13 (Jun. 24, 1943), pp. 337-348.

West, H. R. (2004), An Introduction to Mill's Utilitarian Ethics, Cambridge University Press, Cambridge. 


\section{E-LOGOS}

ELECTRONIC JOURNAL FOR PHILOSOPHY

Ročník/Year: 2011 (vychází průběžně/ published continuously)

Místo vydání/Place of edition: Praha

ISSN 1211-0442

Vydává/Publisher:

Vysoká škola ekonomická v Praze / University of Economics, Prague

nám. W. Churchilla 4

Czech Republic

13067 Praha 3

IČ: 61384399

Web: http://e-logos.vse.cz

Redakce a technické informace/Editorial staff and technical information:

Miroslav Vacura

vacuram@vse.cz

Redakční rada/Board of editors:

Ladislav Benyovszky (FHS UK Praha, Czech Republic)

Ivan Blecha (FF UP Olomouc, Czech Republic)

Martin Hemelík (VŠP Jihlava, Czech Republic)

Angelo Marocco (Pontifical Athenaeum Regina Apostolorum, Rome, Italy)

Jozef Kelemen (FPF SU Opava, Czech Republic)

Daniel Kroupa (ZU Plzeň, Czech Republic)

Vladimír Kvasnička (FIIT STU Bratislava, Slovak Republic)

Jaroslav Novotný (FHS UK Praha, Czech Republic)

Jakub Novotný (VŠP Jihlava, Czech Republic)

Ján Pavlík (editor-in-chief) (VŠE Praha, Czech Republic)

Karel Pstružina (VŠE Praha, Czech Republic)

Miroslav Vacura (executive editor) (VŠE Praha, Czech Republic) 